\title{
The Effect of 16-Minute Thermal Stress and 2-Minute Cold Water Immersion on the Physiological Parameters of Young Sedentary Men
}

\author{
Robert Podstawski', Krzysztof Borysławski², Cain C.T. Clark³, Jari A. Laukkanen ${ }^{4,5}$, Piotr \\ Gronek $^{6}$
}

\begin{abstract}
Affiliations: 'University of Warmia and Mazury in Olsztyn, Faculty of Environmental Sciences, Department of Tourism, Recreation and Ecology, Olsztyn, Poland, ${ }^{2}$ Wrocław University of Life and Environmental Sciences, Department of Anthropology, Wrocław, Poland, ${ }^{3}$ Coventry University, Faculty of Health and Life Sciences, Coventry, United Kingdom, ${ }^{4}$ University of Jyväskylä, Faculty of Sport and Health Sciences, Finland and Central Finland Health Care District Hospital District, Jyväskylä, Finland, IInstitute of Public Health and Clinical Nutrition, University of Eastern Finland, Kuopio, Finland, ${ }^{6}$ University of Physical Education in Poznan, Department of Dance and Gymnastics, Poznan, Poland
\end{abstract}

Correspondence: R. Podstawski, University of Warmia and Mazury in Olsztyn, Faculty of Environmental Sciences, ul. M. Oczapowskiego 5, 10-719 Olsztyn, Poland. E-mail: podstawskirobert@gmail.com

ABSTRACT This study aimed to determine the effect of 16 minutes of thermal stress followed by 2 minutes of cold water immersion on the physiological parameters of fifty-five sedentary men (mean age $20.15 \pm 1.30$ years), who were exposed to 16 minutes of sauna (temperature: $90-91^{\circ} \mathrm{C}$; relative humidity: 14-16\%) followed by 2 minutes of cold water immersion $\left(12^{\circ} \mathrm{C}\right)$. The participants' somatic characteristics were determined before entering the sauna, and their body mass and blood pressure were measured before and after sauna treatment. Physiological parameters were monitored during the 16-minute sauna session and the 2-minute cold water immersion (CRIO) or shower. The subjects perspired 0.21-0.27 litres during the 18-minute session. Heart rate values did not differ significantly between groups during the 16-minute sauna session, but significantly $(\mathrm{p}<0.001)$ lower HR values were noted in the CRIO group than in the control group (68.6:105.7 and 57.5:90.7 bpm). The values of SBP and DBP did not differ significantly between groups before the sauna but were significantly $(\mathrm{p}<0.001)$ lower in the CRIO group after sauna (SBP - 122.0:127.3 mmHg, DBP - 89.9:76.3 mmHg). In both groups, the participants remained within the easy effort range during most of the 18-minute session (650.9 and $492.6 \mathrm{~s}$ ). A 16-minute sauna session followed by 2 minutes of cold water immersion induces a significantly greater decrease in HR and BP (SBP and DBP) than a 16-minute sauna session followed by 30 seconds in the shower and a $90 \mathrm{~s}$ resting period. During cold water immersion, $\mathrm{HR}$ values often decrease to the bradycardia range. Heart rate increased steadily in both groups.

KEY WORDS Finnish sauna, cryotherapy, sedentary men, physiological parameters, somatic features, body composition

$@ M J S S M o n t e n e g r o$

THE EFFECT OF THERMAL STRESS AND COLD WATER IMMERSION

http://mjssm.me/?sekcija=article\&artid=193

\section{Introduction}

The sauna is a type of physical activity (PA) that is highly popular in Scandinavia in all age groups (Hussain \& Cohen, 2018). This form of passive heat therapy is widely used for relaxation and pleasure (Laukkanen et al., 2018). Sauna bathing is renowned for its health benefits, and many users, in particular in the Scandinavian countries, visit a sauna at least once a week to improve their health (Kukkonen-Harjula \& Kauppinen, 2006). For this reason, the majority of studies investigating the benefits of and contraindications to sauna bathing have been conducted in Finland since the late 1970s (Eisalo \& Luurila, 1988; Hannuksela \& Ellahham, 2001; Kauppinen, 1989 a, b, c; Kauppinen \& Voori, 1986; Koljonen, 2009; Kosunen, Pakarinen, Kouppasalmi, \& Adlercreutz, 1976; Kukkonen-Harjula \& Kauppinen, 2006; Leppäluoto, Tuominen, Väänänen, Karpakka, \& Vouri, 1986; Luurila, 1980; Vuori, 1987). Over the years, the influence of sauna bathing on physiological parameters has attracted the interest of researchers from other countries. 
A single sauna session induces changes in the cardiovascular system, including vasodilation, redistribution of blood flow, and increase in sweating as the body attempts to maintain homeostasis under exposure to heat. The high temperature during sauna bathing induces acute physiological responses, fluid loss, and an increase in heart rate (Boraczyński, Boraczyński, Podstawski, Borysławski, \& Jankowski, 2018; Hannuksela \& Ellahham, 2001; Kukkonen-Harjula \& Kauppinen, 2006). Sauna bathing activates various bodily systems, including the endocrine system, which promotes adrenalin secretion (Jezová, Kvestnanský, \& Vigaš, 1994; Kukkonen-Harjula \& Kauppinen, 2006; Leppäluoto et al., 1986; Pilch, Szyguła, Tori, \& Hackney, 2008; Pilch et al., 2010).

Regular sauna use improves adaptability to various environmental conditions, increases physical effort (Blum \& Blum, 2007) and contributes to emotional wellbeing (Podstawski, Choszcz, Honkanen, Tuohino, \& Kolankowska, 2016). Repeated sauna therapy has been shown to increase left ventricular ejection fraction, reduce the levels of plasma norepinephrine and brain natriuretic peptides, and improve performance in a 6-min walk test (Ohori et al., 2012). Diastolic blood pressure (DBP) decreased substantially after one week of repeated sauna use (twice a day) (Leppäluoto et al., 1986). Sauna exposure increases core temperature and induces similar changes in cardiovascular hemodynamics, cardiac output and vascular shear stress as exercise; therefore; it could be regarded as an alternative method of improving health (Brunt, Howard, Francisco, Ely, \& Minson, 2016). Flow-mediated endothelium-dependent dilation improved significantly in patients with cardiovascular risk factors who participated in a two-week trial involving single daily exposure to an infrared sauna (Imamura et al., 2001). A long-term general population-based prospective study revealed that frequent bathing in a Finnish sauna delivered numerous health benefits by lowering the risk of hypertension, dementia, fatal cardiovascular outcomes and all-cause mortality (Laukkanen, Kunutsor, Kauhanen, \& Laukkanen., 2016; Zaccardi et al., 2017).

Cold-water immersion (CWI) is thought to influence the body by stimulating cold- and baroreceptors and by activating the sympathetic nervous system and endocrine function. In turn, these responses may influence water balance and cardiovascular control functions (Epstein, 1992). The hypothesis that cold-induced responses are mainly caused by increased activity of the sympathetic nervous system, whereas water-immersion induced responses are mediated by humoral control mechanisms has been supported by findings by Šrámek, Šimečková, Janskȳ, Savliková, and Vybiral (2000), who found that one-hour head-out immersions in $32^{\circ} \mathrm{C}, 20^{\circ} \mathrm{C}$, and $14^{\circ} \mathrm{C}$ water did not increase blood concentrations of cortisol and that changes in rectal temperature did not correlate with changes in hormone production. However, CWI was effective for maintaining repeat cycling performance in the heat, and this improvement in performance was associated with changes in core temperature and limb blood flow (Vaile et al. 2009). In another study with cyclists, five-minute periods of CWI significantly lowered rectal temperature and maintained endurance performance during subsequent high-intensity exercise (Abbiss, Watson, Nosaka, \& Laursen, 2008). Taken together, these studies indicate that repeat exercise performance in heat may be improved when short periods of cold-water immersion are applied during recovery periods (Peiffer, Abbiss, Watson, Nosaka, \& Laursen, 2008). A similar conclusion was reached by Gill, Beaven, and Cook (2006), who found that the use of cold and hot water immersion improved post-match recovery in elite rugby players.

The physiological effect of thermal stress followed by cold water immersion has never been explored in sedentary individuals who are sporadic sauna users. There is a general lack of evidence to demonstrate the positive effects of such treatment on cardiovascular function and the potential reduction of the risk of cardiovascular disease (CVD) (Laukkanen et al., 2018). Therefore, the aim of this study was to evaluate the effect of thermal stress and cold water immersion on physiological parameters in men with low habitual levels of physical activity who use the sauna sporadically.

\section{Methods}

Participants

A total of 55 male university students aged $18-23$ years (mean=20.15, SD=1.30) volunteered for the study. The participants were divided into two groups: the CRIO group of 30 subjects (who remained immersed in cold water to neck level for 2 minutes immediately after sauna) and the SHOWER group of 25 subjects (who took a cold shower for 30 seconds immediately after sauna and then rested in a sitting position for 90 seconds). The participants were informed about the purpose of the study during obligatory physical education (PE) classes at the University of Warmia and Mazury in Olsztyn. The subjects attended only mandatory PE classes (90 min per week); they did not participate in any extra-curricular PA programmes and had visited the sauna only sporadically before the study. The students did not take any medication or nutritional supplements, were in good health, and had no history of disease affecting biochemical and biomechanical factors. None of the evaluated participants had respiratory or circulatory ailments. Their PA levels were evaluated using the standardized and validated International Physical Activity Questionnaire (IPAQ) (Lee, Macfarlane, Lam, \& Stewart, 2011). The IPAQ was used only to select a homogenous sample of male students, and the results were presented only in terms of Metabolic Equivalent of Task (MET) units indicative of the participants' PA levels. The students declared the number of minutes dedicated to PA (minimum 10 minutes) during an average week preceding the study. The energy expenditure associated with weekly PA levels was expressed in terms of MET units, where the MET is the ratio of the work metabolic rate to the resting metabolic rate, and 1 MET denotes the amount of oxygen consumed in 1 minute at rest, which is estimated at $3.5 \mathrm{~mL} / \mathrm{kg} / \mathrm{min}$. Based on the frequency, intensity and duration of the PA levels declared by the surveyed students, the respondents were classified into groups characterized by low ( $\mathrm{L}<600$ METs-min/week), moderate $(\mathrm{M}<1,500 \mathrm{METs}$-min/ week) and high ( $\mathrm{H} \geq 1,500 \mathrm{METs}-\mathrm{min} /$ week) levels of activity. Only male students with low levels of PA (energy expenditure of up to 600 METs per week) and a sedentary lifestyle were chosen for the study. All participants gave their written informed consent to participate in the study. The study was conducted in line with the guidelines of 
the University of Warmia and Mazury in Olsztyn (UWM), Poland, the ethics committee, and the provisions of the Declaration of Helsinki.

\section{Instruments and procedures}

The participants received comprehensive information about sauna rules before the study. They were instructed to drink at least one litre (L) of water on the day before the test and $0.5 \mathrm{~L}$ of water 2 hours before the test. During the study, every participant remained in a dry sauna (temperature: $90-92 \mathrm{oC}$; relative humidity: $14-16 \%$ ) in a seated position for 16 minutes. The students assigned to the CRIO group cooled down in a paddling pool (pool width: $100 \mathrm{~cm}$; pool depth: $130 \mathrm{~cm}$; water temperature: $+10-11 \mathrm{oC}$ ) for two minutes immediately after the 16-minute sauna session. The students assigned to the SHOWER group took a cold shower $\left(10-11^{\circ} \mathrm{C}\right)$ lasting around 30 seconds directly after sauna and then rested in a sitting position for 90 seconds in a neutral compartment (i.e., a room with a temperature of $20-22^{\circ} \mathrm{C}$ and relative air humidity of approximately $50 \%$ ).

Body height was measured to the nearest $0.1 \mathrm{~mm}$ with a stadiometer, and nude body mass was measured to the nearest $0.1 \mathrm{~kg}$ with a calibrated WB-150 medical scale (ZPU Tryb Wag, Poland) prior to the first sauna session. The measured values were used to calculate the participants' BMI. Blood pressure (BP) was determined with an automatic digital blood pressure monitor (Omron M6 Comfort, Japan) immediately before sauna and during cooldown at room temperature. Somatic features, including body mass, body mass index (BMI), body surface area (BSA) and the waist-hip ratio (WHR), as well as body composition parameters, including body mass, total body water (TBW), protein and mineral content, body fat mass (BFM), fat-free mass (FFM), skeletal muscle mass (SMM), percentage body fat (PBF), InBody score, target weight, visceral fat level (VFL), basal metabolic rate (BMR) and degree of obesity, were determined via bioelectrical impedance (Gibson, Holmes, Desautels, Edmonds, \& Nuudi, 2008) with the InBody 720 body composition analyser. Due to high temperature in the sauna, physiological parameters, including heart rate (HR min, avg, max), recovery time, peak training effect (PTE), energy expenditure, oxygen uptake (VO2 avg, max), excess post-exercise oxygen consumption (EPOC avg, peak), respiratory rate (avg, max) and physical effort (easy, moderate, difficult, very difficult, maximal), were measured indirectly with Suunto Ambit3 Peak heart rate monitors which are widely used in studies of the type (Scoon, Hopkins, Mayhew, \& Cotter, 2007). Every pulsometer was calibrated to the male sex, year of birth, body mass and PA level before sauna exposure.

\section{Statistical analysis}

Measurement results were processed statistically in the Statistica PL v. 13.5 application with the use of descriptive statistics. The analysed parameters were tested for normal distribution. Arithmetic means were compared by the Student's t-test at a significance level of $\mathrm{p} \leq 0.05$.

TABLE 1. Descriptive statistics of the studied anthropometric and body composition parameters in (CRIO) and (SHOWER) groups

\begin{tabular}{|c|c|c|c|c|c|c|c|c|c|c|}
\hline \multirow{2}{*}{ Parameters } & \multicolumn{4}{|c|}{ 1. CRIO $(n=30)$} & \multicolumn{4}{|c|}{ 2. SHOWER $(n=25)$} & \multicolumn{2}{|c|}{ Difference (1-2) } \\
\hline & Mean & SD & min-max & As & Mean & SD & $\min -\max$ & As & $t$ & $p$ \\
\hline Age [years] & 20.07 & 1.34 & $18-23$ & 0.24 & 20.24 & 1.27 & $18-22$ & 0.04 & -0.49 & ns \\
\hline Body height $[\mathrm{cm}]$ & 179.64 & 7.13 & $166.0-196.2$ & 0.12 & 180.02 & 6.10 & $166.0-192.3$ & -0.27 & -0.21 & ns \\
\hline Body mass before sauna [kg] & 85.03 & 12.94 & $55.9-109.9$ & -0.07 & 83.84 & 10.31 & $58.0-99.7$ & -0.88 & 0.37 & ns \\
\hline Body mass after sauna [kg] & 84.82 & 12.91 & $55.7-109.7$ & -0.07 & 83.57 & 10.22 & $57.9-99.4$ & -0.89 & 0.39 & ns \\
\hline BML (Body Mass Loss) [kg] & 0.21 & 0.08 & $0.1-0.4$ & 0.34 & 0.27 & 0.22 & $0.1-1.2$ & 3.59 & -1.35 & ns \\
\hline Weight Control [kg] & -4.98 & 6.54 & $-16.8-7.9$ & 0.17 & -4.760 & 7.53 & $-16.2-19.2$ & 1.48 & -0.12 & ns \\
\hline BMI (Body Mass Index) [kg/m²] & 26.31 & 3.41 & 19.34-33.07 & -0.28 & 25.93 & 3.40 & $16.79-31.32$ & -1.07 & 0.41 & ns \\
\hline BSA (Body Surface Area) $\left[m^{2}\right]$ & 2.06 & 0.18 & $1.63-2.37$ & -0.22 & 2.05 & 0.14 & $1.69-2.31$ & -0.67 & 0.26 & ns \\
\hline WHR (Waist-Hip Ratio) & 0.89 & 0.07 & $0.77-1.03$ & 0.11 & 0.89 & 0.08 & $0.72-1.01$ & -0.68 & 0.10 & ns \\
\hline TBW (Total Body Water) [L] & 49.57 & 6.56 & $32.9-60.5$ & -0.52 & 49.57 & 5.03 & $41.9-61.7$ & 0.69 & 0.00 & ns \\
\hline Proteins [kg] & 13.46 & 1.81 & $8.9-16.4$ & -0.53 & 13.34 & 1.46 & $10.7-16.8$ & 0.58 & 0.28 & ns \\
\hline Minerals [kg] & 4.62 & 0.68 & $3.24-5.59$ & -0.35 & 4.61 & 0.53 & $3.55-5.71$ & -0.40 & 0.07 & ns \\
\hline SMM (Skeletal Muscle Mass) [kg] & 38.64 & 5.49 & $24.7-47.6$ & -0.53 & 38.22 & 4.38 & $30.4-48.5$ & 0.56 & 0.31 & ns \\
\hline PBF (Percent Body Fat) [\%] & 20.00 & 5.4930 & $11.3-30.3$ & 0.12 & 19.70 & 6.37 & $6.7-29.9$ & -0.59 & 0.19 & ns \\
\hline BFM (Body Fat Mass) [kg] & 17.33 & 6.34 & $7.9-30.8$ & 0.24 & 16.87 & 6.32 & $3.9-27.8$ & -0.48 & 0.27 & ns \\
\hline BF-LBM Control [kg] & -5.57 & 5.65 & $-16.8-3.3$ & -0.30 & -5.42 & 5.81 & $-16.2-6.9$ & 0.32 & -0.09 & ns \\
\hline FFM (Fat Free Mass) [kg] & 67.71 & 9.06 & $45.0-82.5$ & -0.50 & 67.01 & 7.17 & $54.1-84.2$ & 0.56 & 0.31 & ns \\
\hline FFM Control [kg] & 0.57 & 1.91 & $0.0-9.1$ & 3.73 & 0.66 & 2.55 & $0.0-12.3$ & 4.40 & -0.14 & ns \\
\hline Target weight & 80.07 & 9.59 & $63.0-97.0$ & -0.18 & 79.08 & 7.34 & $68.2-99.0$ & 0.75 & 0.41 & ns \\
\hline MET & 478.6 & 68.0 & $397-599$ & 0.38 & 470.1 & 66.4 & $387-590$ & 0.55 & 0.47 & ns \\
\hline
\end{tabular}

Results

No significant differences in age, somatic or anthropometric parameters were observed between the CRIO 
group and the SHOWER group, which suggests that the analysed groups were homogeneous and could be compared. In both groups, the participants' BMI values approximated the overweight threshold (26.3 and $25.93 \mathrm{~kg} / \mathrm{m} 2$, respectively). Only $27.3 \%$ of the studied subjects had a BMI below 25 . The waist-to-hip ratio was identical in both groups (0.89), and it was not indicative of obesity. The students perspired 0.21-0.27 litres during the 18-minute treatment (16 minutes of sauna, followed by 2 minutes of cooldown). The values of Body Fat-Lean Body Mass Control indicate that the participants should lose 5.42-5.57 kg of body fat mass and gain $0.57-0.66 \mathrm{~kg}$ of fat-free mass. Both groups were characterized by low and statistically similar PA levels.

TABLE 2. Descriptive statistics of HR values in (CRIO) and (SHOWER) groups

\begin{tabular}{|c|c|c|c|c|c|c|c|c|c|c|}
\hline \multirow{2}{*}{ HR [bpm] } & \multicolumn{5}{|c|}{ 1. $C R I O(n=30)$} & \multicolumn{3}{|c|}{ 2. SHOWER $(n=25)$} & \multicolumn{2}{|c|}{ Difference (1-2) } \\
\hline & Mean & SD & $\min -\max$ & As & Mean & SD & $\min -\max$ & As & $t$ & $p$ \\
\hline $\mathrm{HR}_{\mathrm{BS}}$ & 82.1 & 10.7 & $68-119$ & 1.49 & 80.2 & 8.1 & $61-98$ & -0.06 & 0.76 & ns \\
\hline $\mathrm{HR}_{\text {AS+cryo }} \mathrm{O}_{\mathrm{r} S+\text { showe }}{ }^{\mathrm{r}}$ & 66.2 & 6.0 & $52-77$ & -0.26 & 85.2 & 7.5 & $72-99$ & -0.11 & -10.41 & $<0.001$ \\
\hline $\mathrm{HR}_{\text {min }}$ & 57.4 & 6.9 & $46-70$ & 0.20 & 80.1 & 9.6 & $61-102$ & 0.29 & -10.14 & $<0.001$ \\
\hline $\mathrm{HR}_{\mathrm{avg}}$ & 104.1 & 8.5 & $89-122$ & 0.12 & 109.5 & 8.3 & $91-122$ & -0.19 & -2.34 & 0.023 \\
\hline $\mathrm{HR}_{\max }$ & 128.1 & 7.5 & 114-141 & 0.18 & 129.5 & 6.7 & $112-141$ & -0.89 & -0.75 & ns \\
\hline $\mathrm{HR}_{1 \min }$ & 84.9 & 7.4 & $72-98$ & 0.06 & 83.2 & 9.4 & 63-101 & 0.05 & 0.73 & ns \\
\hline $\mathrm{HR}_{2 \min }$ & 89.6 & 7.7 & $81-112$ & 1.41 & 89.9 & 8.1 & $79-106$ & 0.43 & -0.17 & ns \\
\hline $\mathrm{HR}_{4 \min }$ & 94.3 & 7.3 & 83-113 & 1.16 & 96.1 & 7.6 & $82-111$ & 0.19 & -0.91 & ns \\
\hline $\mathrm{HR}_{6 \min }$ & 99.1 & 8.3 & $88-120$ & 0.89 & 102.5 & 8.6 & $85-117$ & -0.31 & -1.47 & ns \\
\hline $\mathrm{HR}_{8 \min }$ & 105.9 & 7.7 & $91-126$ & 0.72 & 106.0 & 8.7 & $87-124$ & -0.25 & -0.05 & ns \\
\hline $\mathrm{HR}_{10 \text { min }}$ & 108.8 & 8.5 & 89-127 & -0.01 & 111.1 & 8.8 & $91-125$ & -0.53 & -0.98 & ns \\
\hline $\mathrm{HR}_{12 \min }$ & 114.0 & 8.6 & $92-130$ & -0.54 & 114.9 & 8.5 & $96-133$ & -0.03 & -0.41 & ns \\
\hline $\mathrm{HR}_{14 \min }$ & 120.1 & 6.7 & $106-132$ & -0.21 & 119.6 & 7.9 & $103-133$ & -0.41 & 0.24 & ns \\
\hline $\mathrm{HR}_{16 \min }$ & 126.3 & 8.5 & 111-141 & 0.09 & 128.5 & 6.6 & $112-137$ & -0.78 & -1.08 & ns \\
\hline $\mathrm{HR}_{17 \text { min }}$ & 68.6 & 6.2 & $57-91$ & 1.31 & 105.7 & 14.6 & $65-126$ & -1.37 & -12.62 & $<0.001$ \\
\hline $\mathrm{HR}_{18 \text { min }}$ & 57.5 & 6.8 & $46-70$ & 0.15 & 90.7 & 12.7 & $61-113$ & -0.48 & -12.40 & $<0.001$ \\
\hline
\end{tabular}

Notes: HRBS - heart rate before sauna, HRAS+crio or S+shower - heart rate after sauna + cryotherapy or sauna + shower.

Before the sauna, HR values did not differ significantly between groups ( 82.1 and $80.2 \mathrm{bpm}$, respectively), but HR values determined directly after the 18 -minute session were significantly $(\mathrm{p}<0.001)$ lower in the CRIO group than in the SHOWER group $(66.2 \pm 6.0$ and $85.2 \pm 7.5 \mathrm{bpm}$, respectively). The measurements conducted during the 16-minute sauna session did not reveal significant differences in HR between

TABLE 3. Descriptive statistics of the studied physiological parameters in (CRIO) and (SHOWER) groups

\begin{tabular}{|c|c|c|c|c|c|c|c|c|c|c|c|}
\hline \multirow{2}{*}{\multicolumn{2}{|c|}{ Traits }} & \multicolumn{4}{|c|}{ 1. CRIO $(n=30)$} & \multicolumn{4}{|c|}{ 2. SHOWER $(n=25)$} & \multicolumn{2}{|c|}{ Difference (1-2) } \\
\hline & & Mean & SD & $\min -\max$ & As & Mean & SD & $\min -\max$ & As & $t$ & $p$ \\
\hline \multicolumn{2}{|c|}{ Energy expenditure [kcal] } & 143.80 & 17.31 & $103-183$ & -0.31 & 145.68 & 20.85 & $102-184$ & -0.09 & -0.37 & ns \\
\hline \multirow{2}{*}{$\mathrm{VO}_{2}[\mathrm{~mL} / \mathrm{kg} / \mathrm{min}]$} & avg & 15.27 & 2.59 & $11-22$ & 0.80 & 16.96 & 3.18 & $12-23$ & 0.39 & -2.18 & 0.034 \\
\hline & $\max$ & 22.50 & 3.01 & $17-28$ & 0.29 & 24.60 & 3.56 & $19-33$ & 0.47 & -2.37 & 0.021 \\
\hline \multirow{2}{*}{$\mathrm{EPOC}[\mathrm{mL} / \mathrm{kg}]$} & avg & 4.37 & 2.40 & $2-10$ & 0.93 & 5.68 & 3.06 & $2-12$ & 0.61 & -1.78 & ns \\
\hline & $\max$ & 9.33 & 5.60 & $4-23$ & 1.01 & 12.80 & 6.28 & $4-28$ & 0.71 & -2.16 & 0.036 \\
\hline \multirow{2}{*}{$\begin{array}{l}\text { Systolic blood } \\
\text { pressure-SBP [mmHg] }\end{array}$} & before sauna & 130.5 & 9.2 & $107-147$ & 0.29 & 131.0 & 9.6 & $117-153$ & 0.37 & -0.20 & ns \\
\hline & after sauna & 122.0 & 7.3 & $105-136$ & -0.33 & 127.3 & 7.8 & $114-146$ & 0.14 & -2.57 & 0.012 \\
\hline \multirow{2}{*}{$\begin{array}{l}\text { Diastolic blood pressure- } \\
\text { DBP }[\mathrm{mmHg}]\end{array}$} & before sauna & 77.8 & 11.4 & $53-113$ & 0.58 & 78.6 & 8.0 & $66-97$ & 0.34 & -0.31 & ns \\
\hline & after sauna & 69.9 & 8.7 & $50-83$ & -0.40 & 76.3 & 8.4 & $65-99$ & 0.83 & -2.76 & 0.008 \\
\hline \multicolumn{12}{|c|}{ Physical effort range [s] } \\
\hline \multicolumn{2}{|c|}{ Easy <107 [bpm] } & 650.9 & 264.7 & $189-1080$ & -0.17 & 492.6 & 267.3 & $57-1004$ & 0.16 & 2.19 & 0.032 \\
\hline \multicolumn{2}{|c|}{ Moderate 107-124 [bpm] } & 346.5 & 190.8 & $0-725$ & -0.02 & 415.2 & 208.6 & $76-1023$ & 1.18 & -1.26 & ns \\
\hline \multicolumn{2}{|c|}{ Difficult 125-141 [bpm] } & 82.6 & 121.3 & $0-444$ & 1.68 & 164.4 & 183.7 & $0-626$ & 1.19 & -1.97 & ns \\
\hline \multicolumn{2}{|c|}{ Very difficult 142-159 [bpm] } & 0.1 & 0.4 & $0-2$ & 5.48 & 8.0 & 36.4 & $0-182$ & 4.93 & -1.19 & ns \\
\hline \multicolumn{2}{|c|}{ Maximal $\geq 160[\mathrm{bpm}]$} & \multicolumn{10}{|c|}{ All values are zero } \\
\hline
\end{tabular}


groups. However, HR values determined in the 17 th and 18 th minute were significantly $(p<0.001)$ lower in the CRIO group (for 37.1 and $33.2 \mathrm{bpm}$, respectively) than in the SHOWER group (17th minute 68.6:105.7 bpm, 18th minute $-57.5: 90.7 \mathrm{bpm})$. As a result, the average HR was also significantly $(\mathrm{p}=0.023)$ lower (by $5.4 \mathrm{bpm}$ ) in the CRIO group than in the SHOWER group (HRavg - 104.1:109.5 bpm).

The average estimated values of VO2avg ( $15.27 \mathrm{~mL} / \mathrm{kg} / \mathrm{min}), \mathrm{VO} 2 \mathrm{max}(22.5 \mathrm{~mL} / \mathrm{kg} / \mathrm{min})$, EPOCavg (4.37 $\mathrm{mL} / \mathrm{kg})$ and EPOCmax $(9.33 \mathrm{~mL} / \mathrm{kg})$ were significantly higher in the SHOWER group than in the CRIO group (for: 1.7 and $2.1 \mathrm{~mL} / \mathrm{kg} / \mathrm{min}$, as well as 1.3 and $4.4 \mathrm{~mL} / \mathrm{kg}$, respectively). The differences in BP values were similar to those noted in HR values. The values of SBP and DBP did not differ significantly between groups before the sauna but were significantly lower in the CRIO group after it (SBP - 122.0:127.3 $\mathrm{mmHg}$, DPB - 89.9:76.3 mmHg). The participants from the CRIO group remained within the easy effort range significantly $(\mathrm{p}=0.032)$ longer than the males from the SHOWER group (650.9: $492.6 \mathrm{~s})$. The students from the SHOWER group remained within the moderate (415.2: $346.5 \mathrm{~s}$ ), difficult and very difficult effort rate longer than the participants from the CRIO group, but the noted differences were not significant $(\mathrm{p}>0.05)$.

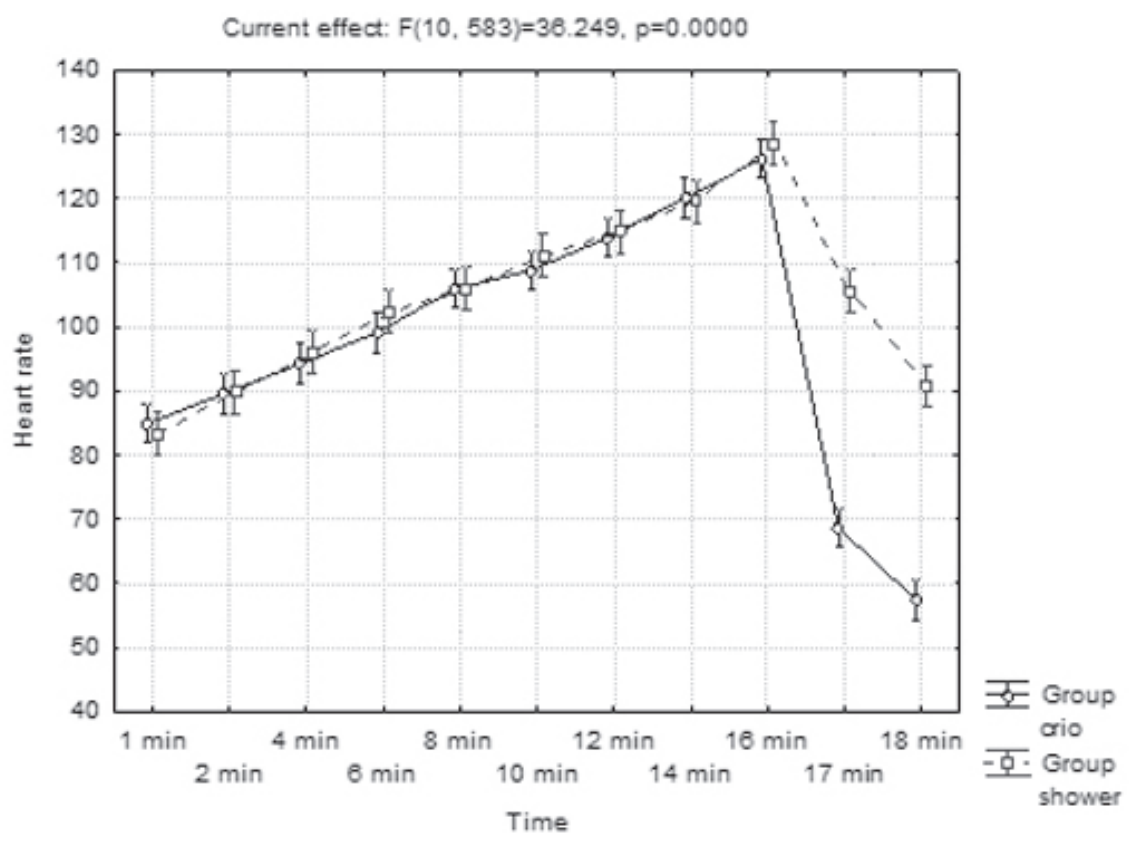

FIGURE 1. Changes in HR values at 1-minute and 2-minute intervals in CRIO and SHOWER groups

The average HR values increased at a similar rate during sauna in both groups, but HR measured in the 17 th and 18th minutes decreased at a significantly higher rate in the CRIO group (immersion in cool water with a temperature of $11-12^{\circ} \mathrm{C}$ ).

In both groups, HR increased at a relatively steady rate of $2.70 \mathrm{bpm}$. Lower values were noted only between the 8 th and 10th minute $(1.9 \mathrm{bpm})$, and higher values were observed between the 14th and 16th minutes (3.7 bpm).

Clear differences in recovery HR were found between the analysed groups. The greatest decrease in HR

TABLE 4. Changes in heart rate during sauna at one-minute intervals (up to the $16^{\text {th }}$ minute)

\begin{tabular}{cccc} 
Time $[$ min] & \multicolumn{3}{c}{ CRIO + SHOWER (n=55) [bpm] } \\
\cline { 2 - 4 } & Mean & SD & min $\div$ max \\
\hline $1^{*}-2$ & 2.8 & 2.7 & $-4 \div 13$ \\
$2-4$ & 2.7 & 2.2 & $-3 \div 8$ \\
$4-6$ & 2.8 & 2.1 & $-2 \div 10$ \\
$6-8$ & 2.7 & 2.2 & $-4 \div 9$ \\
$8-10$ & 1.9 & 2.4 & $-6 \div 12$ \\
$10-12$ & 2.3 & 2.0 & $-7 \div 6$ \\
$12-14$ & 2.7 & 2.2 & $-2 \div 10$ \\
$14-16$ & 3.7 & 2.7 & $-3 \div 10$ \\
\hline
\end{tabular}

Note: * starting from the first second of sauna use. 
was observed between the 16th and 17th minutes (one minute after sauna) in both groups (-57.6 and $-22.8 \mathrm{bpm}$, respectively). One minute after the sauna, the decrease in HR was significantly $(\mathrm{p}<0.001)$ higher in the CRIO group than in the SHOWER group. In the second minute after the sauna, the decrease in HR was significantly $(\mathrm{p}=0.049)$ higher in the SHOWER group $(-15 \mathrm{bpm})$.

\begin{tabular}{|c|c|c|c|c|c|c|c|c|}
\hline \multirow{2}{*}{ Time [min] } & \multicolumn{3}{|c|}{ 1. CRIO (n=30) [bpm] } & \multicolumn{3}{|c|}{ 2. SHOWER $(n=25) \mathrm{bpm}]$} & \multicolumn{2}{|c|}{ Difference(1-2) } \\
\hline & Mean & SD & $\min \div \max$ & Mean & SD & $\min \div \max$ & $t$ & $p$ \\
\hline $16-17$ & -57.6 & 8.8 & $-73 \div-36$ & -22.8 & 11.5 & $-54 \div-7$ & 12.70 & $<0.001$ \\
\hline $17-18$ & -11.2 & 6.4 & $-35 \div-2$ & -15.0 & 7.6 & $-35 \div-1$ & 2.01 & 0.049 \\
\hline
\end{tabular}

\section{Discussion}

The results of this study provide novel and valuable insights into the physiological responses of young sedentary men to sauna treatment. One sauna session lasting 16 minutes, followed by 2 minutes of immersion in cold water $\left(11-12^{\circ} \mathrm{C}\right)$ induced significant differences in the tested subjects' physiological parameters. The values measured after sauna in the CRIO group differed significantly from those noted in men who took a cold shower for 30 seconds and then rested for 90 minutes in a temperature-neutral room. The post-sauna decrease in HR and BP was significantly more rapid in the CRIO group than in the SHOWER group. The participants' HR values were significantly $(\mathrm{p}<0.001)$ lower $($ HRASC $=66.2 \mathrm{bpm})$ after cold water immersion $(\mathrm{CWI})$ than immediately before the 16 -minute sauna session (HRBSC $=82.1 \mathrm{bpm}$ ). In the SHOWER group, HR values after sauna, shower and relaxation were significantly $(\mathrm{p}=0.028)$ higher (HRASPR $=85.2 \mathrm{bpm})$ than before sauna $($ HRBSPR $=80.2 \mathrm{bpm})$. The above findings could have practical implications for persons who attend multiple rounds of sauna with breaks in between. A study of university students who attended four sauna sessions with 5-minute breaks between sessions under nearly identical conditions to those described in the present study (temperature: $90^{\circ} \mathrm{C}$; relative humidity: $14-16 \%$ ) revealed a steady increase in HRavg during successive sauna sessions, from $98 \mathrm{bpm}$ during the first session to more than $133 \mathrm{bpm}$ during the fourth session (Podstawski et al., 2019). The recovery HR during every successive break also increased and exceeded baseline values, which could indicate that 5-minute breaks after 10-minute sauna sessions are insufficient for full physiological recovery. In young people who regularly use the sauna, HR increases to approximately 100-110 bpm and may exceed 140-150 bpm with a rise in ambient temperature (Hasan, Karvonen, \& Pirronen, 1967; Leppäluoto et al., 1986; Luuira, 1980; Tei et al., 1995). The increase in HR can be even higher in participants who do not use the sauna regularly, which can be attributed to the lack of physiological adaptation to high temperature (Leppäluoto et al., 1986). The rise in HR is also influenced by other factors, such as the length of stay in the sauna, age, sex and physical endurance (Sawicka \& Brzostek, 2007). In terms of health outcomes, the increase in HR to around $120 \mathrm{bpm}$ is regarded as a beneficial adaptive response, whereas an increase in excess of $140 \mathrm{bpm}$ can have adverse consequences because it is associated with higher cardiac effort and diastole shortening (Sawicka \& Brzostek, 2007). In some participants from the SHOWER group, HR reached $141 \mathrm{bpm}$ immediately after 16 minutes of sauna and $113 \mathrm{bpm}$ after the 2 -minute break. In these subjects, HR is likely to exceed normal values after successive sauna sessions. Coldwater immersion between sauna sessions appears to be more effective in cooling the body and speeding up recovery, and it can be recommended for persons who rarely use the sauna. Similar conclusions were formulated by Hasan et al. (1967) who observed that HR decreased slowly during prolonged and gradual body cooling, such as a cold shower. Baseline HR is restored approximately 1-4 hours after sauna if the body is cooled at room temperature.

In the CRIO group, the decrease in HR after CWI was accompanied by a clear drop in BP (SBP and DBP). In the CRIO group, SBP decreased significantly $(\mathrm{p}<0.001)$ by $8.5 \mathrm{mmHg}$, whereas the corresponding decrease in the SHOWER group reached only $3.7 \mathrm{mmHg}$ and was not significant $(\mathrm{p}=0.143)$. In the CRIO group, DBP decreased significantly $(\mathrm{p}=0.004)$ by $7.9 \mathrm{mmHg}$, whereas in the SHOWER group, this corresponding decrease (by $2 \mathrm{mmHg}$ ) was not significant ( $\mathrm{p}=0.327$ ). The above findings indicate that CWI in between sauna sessions leads to a greater decrease in BP than a cold shower followed by a resting period. In the literature, the effects of sauna bathing on BP vary considerably, depending on the applied method of measurement, type of sauna, duration of exposure which elicits the evaporation effect, and user adaptation to high temperature. Considerable variations were reported in studies in which BP was measured with a sphygmomanometer, ranging from a minor increase (Eisalo \& Luurila, 1988; Kukkonen-Harjula \& Kauppinen, 2006) or the absence of any changes (Luuira, 1980, Miyamoto et al., 2005, Rismann, al-Karawi, \& Jorch, 2002), to a decrease in SBP (Gianetti et al., 1999; Kihara et al., 2002, Kiss, Popp, Wagner, Zwick, \& Sertl, 1994; Miyamoto et al., 2005) and DBP values (Hasan \& Karvonen, 1967; Imamura et al., 2001; Kauppinen \& Vuori, 1986; Kihara et al., 2002; Leppäluoto et al., 1986; Luuira, 1980; Kauppinen, 1989; Tei et al., 1995; Tei \& Tanaka, 1996). In the cited studies, BP was measured immediately after sauna, whereas in the current study, the relevant measurements were performed around 30 seconds after the entire session to determine the health benefits of the sauna (several hours after the treatment) rather than the direct effects of thermal stress. In subjects with a higher risk of cardiovascular disease, sauna exposure may improve vascular compliance, which indicates that heat therapy prevents arterial stiffening (Imamura et al., 2001). Sauna bathing is generally well tolerated, but according to some authors, it could increase the risk of myocardial ischemia in patients with coronary artery disease (Giannetti et al., 1999). 
An increase in ambient temperature can decrease blood pressure, which further confirms that passive heat therapy delivers health benefits (Gayda et al., 2012; Kunutsor \& Powles, 2010).

Sauna bathing can also contribute to a decrease in body mass. Sweat volume during sauna bathing is estimated at 0.6 to $1.0 \mathrm{~kg} / \mathrm{h}$, and sweating generally intensifies with a rise in temperature and humidity, although individual responses may vary (Luuira, 1980, Podstawski et al., 2019). In the present study, average perspiration was considerably lower, ranging from $0.21 \mathrm{~kg}$ in the CRIO group to $0.27 \mathrm{~kg}$ in the SHOWER group. Low BML values can be attributed to the relatively short duration of sauna treatment (16 minutes). According to Kauppinen (1989a), peak sweating and significant physiological changes can be observed after at least 15 minutes of sauna use. For this reason, in most published research, the effects of thermal stress on the human body are investigated during longer sauna sessions. The values of BML are significantly correlated not only with anthropometric indicators (in particular body mass, BMI, BSA and WHR) but also with body composition parameters, in particular, those indicative of body fat content (BFM, PBF and VFM) and degree of obesity (Podstawski et al., 2014; Podstawski et al., 2019). In our previous study (Podstawski et al., 2016), BML values measured after sauna bathing were significantly higher in female and male subjects with higher body mass, but they tended to be lower in taller participants (less so in men). With every kilogram increase in body mass, the corresponding BML values increased by $0.0144 \mathrm{~kg}$ in women and $0.0146 \mathrm{~kg}$ in men on average. Kauppinen (1989a) determined the average total sweat secretion during sauna at $0.5 \mathrm{~kg}$. Core body temperature increases by 0.1 to $0.25^{\circ} \mathrm{C}$ per every percentage point of BML (Montain \& Coyle, 1992; Sawka, Young, Francesconi, Muza, \& Pandolf, 1985). One of the first studies into the effect of sweating on the fluid balance was conducted by Kozłowski and Saltin (1964), who analysed sweating-induced dehydration in six healthy males exposed to a temperature of $80^{\circ} \mathrm{C}$ in a sauna for 2.5 hours, which is nearly four times longer than in our study. In the cited study, the average BML during the 2.5-hour sauna session was determined at $3.1 \mathrm{~kg}(4.1 \%)$. In other studies, the average sauna-induced BML was estimated at 400-600 g (Kauppinen \& Vuori, 1986; Hawkins, 1987).

\section{Limitations}

The use of HR monitors for measuring the participants' physiological parameters was a potential limitation of this study. However, the evaluated males were exposed to extreme temperature (from 11 to $90^{\circ} \mathrm{C}$ ), and different measuring equipment could not have been used as effectively in a study conducted on a large and homogenous sample (55 males) with similar environmental conditions (day, hour, duration, temperature and humidity). Future studies may, therefore, wish to examine the reliability and validity of various HR monitors in extreme conditions.

\section{Conclusion}

A 16-minute stay in the sauna followed by 2 minutes of cold water immersion induces a greater decrease in HR and BP (SBP and DBP) than 16 minutes of the sauna by 30 seconds in the shower and a 90 s resting period. During cryotherapy, HR values often decrease to the bradycardia range (below $60 \mathrm{bpm}$ ). In both groups, HR increases steadily at $2.70 \mathrm{bpm}$ on average.

\section{Acknowledgements}

The authors would like to thank all students who volunteered for the study.

\section{Funding}

This work was supported by the University of Warmia and Mazury in Olsztyn.

\section{References}

Blum, N., \& Blum, A. (2007). Beneficial effects of sauna bathing for heart failure patients. Experimental \& Clinical Cardiology, 12(1), 29-32.

Boraczyński, T., Boraczyński, M., Podstawski, R., Borysławski, K., \& Jankowski, K. (2019). Body mass loss in dry sauna and heart rate response to heat stress. Revista Brasileira de Medicina do Esporte, 24(4), 258-262. doi: 10.1590/1517-869220182404172175

Brunt, V.E., Howard, M.J., Francisco, M.A., Ely, B.R., \& Minson, C.T. (2016). Passive heat therapy improves endothelial function, arterial stiffness and blood pressure in sedentary humans. Journal of Physiology, 594(18), 5329-5342. doi: 10.1113/JP272453.

Eisalo, A., \& Laurila, O.J. (1988). The Finnish sauna and cardiovascular disease. Annals of Clinical Research, 20, 267-270.

Epstein, M. (1992). Renal effects of head-out water immersion in humans: a 15-year update. Physiological Review, 72, 563-621.

Gayda, M., Paillard, F., Sosner, P. Juneau, M., Garzon, M., Gonzalez, M., Bélanger, M., \& Nigam, A. (2012). Effects of sauna alone and postexercise sauna baths on blood pressure and hemodynamic variables in patients with untreated hypertension. Journal of Clinical Hypertensio. (Greenwich), 14(8), 553-560. doi: 10.1111/j.1751-7176.2012.00637.x

Gianetti, N., Juneau, M., Arsenault, A., Behr, M.A., Grégoire, J., Tessier, M., \& Larivée, L. (1999). Sauna induced myocardial ischemia. American Journal of Medicine, 107(3), 228-233. doi: 10.1016/S00029343(99)00220-X 
Gibson, A.L., Holmes, J.C., Desautels, R.L.,. Edmonds, L.B., \& Nuudi, L. (2008). Ability of new octopolar bioimpedance spectroscopy analyzers to predict 4-component-model percentage body fat in Hispanic, black, and white adults, American Journal of Clinical Nutrition, 87(2), 332-338. doi: 10.1093/ajcn/87.2.332

Gill, N.D., Beaven, C.M., \& Cook, C. (2006). Effectiveness of post-match recovery strategies in rugby players. British Journal of Sports Medicine, 40(3), 260-263. doi: 10.1136/bjsm.2005.022483

Hannuksela, M., \& Ellahham, S. (2001). Benefits and risks of sauna bathing. American Journal of Medicine, 110(2), 118-126. doi: 10.1016/s0002-9343(00)00671-9

Hasan, J., Karvonen, M.J. \& Pirronen, P.(1967). Special review. II. Physiological effects of extreme heat. As studied in the Finnish "sauna" bath. American Journal of Physical Medicine, 46, 1226-1246.

Hawkins, C. (1987). The sauna: killer or healer? British Medicine Journal, 295(6605), 1015-1016. doi: 10.1136/ bmj.295.6605.1015-a

Hussain, J., \& Cohen, M. (2018). Clinical effects of regular dry sauna bathing: A systematic review. EvidenceBased Complementary and Alternative Medicine, 2018, 1857413, doi: 10.1155/2018/1857413

Imamura, M., Biro, S., Kihara, T., Yoshifuku, S., Takasaki, K., Otuji, Y. (2001). Repeated thermal therapy improves impaired vascular endothelial function in patients with coronary risk factors. Journal of the American College of Cardiology, 38(4), 1083-1088. doi: 10.1016/s0735-1097(01)01467-x

Jezová, D., Kvestnanský, R., Vigaš, M. (1994). Sex differences in endocrine response to hyperthermia in sauna. Acta Physiologica Scandinavica, 150(3), 293-298. doi: 10.1111/j.1748-1716.1994.tb09689.x

Kauppinen, K. (1989a). Sauna, shower, and ice water immersion. Physiological responses to brief exposures to heat, cool, and cold. Part I. Body fluid balance. Arctic Medical Research, 48(2), 55-63.

Kauppinen, K. (1989b). Sauna, shower, and ice water immersion. Physiological responses to brief exposures to heat, cool, and cold. Part II. Circulation. Arctic Medical Research, 48(2), 64-74.

Kauppinen, K. (1989c). Sauna, shower, and ice water immersion. Physiological responses to brief exposures to heat, cool, and cold. Part III. Body temperatures. Arctic Medical Research, 48(2), 75-86.

Kauppinen, K., Vuori, I. (1986). Man in the sauna. Annals of Clinical Research, 18, 173-185.

Kihara, T., Biro, S., Imamura, M., Yoshifuku, S., Takasaki, K., Ikeda, Y., Otuji, Y., Minagoe, S., Toyama, Y., \& Tei, C. (2002). Repeated sauna treatment improves vascular endothelial and cardiac function in patients with chronic heart failure. Journal of the American College of Cardiology, 39(5), 754-759. doi: 10.1016/ s0735-1097(01)01824-1

Kiss, D., Popp., W, Wagner., C, Zwick., H., \& Sertl, K. (1994). Effects of the sauna on diffusing capacity, pulmonary function and cardiac output in healthy subjects. Respiration, 61(2), 86-88. doi: 10.1159/000196312

Koljonen, V. (2009). Hot air sauna burns - review of their etiology and treatment. Journal of Burn Care Research, 30(4), 701-710. doi: 10.1097/BCR.0bo13e3181abfa9f.

Kosunen, K., Pakarinen, J., Kouppasalmi, K., \& Adlercreutz, H. (1976). Plasma renin activity, angiotensin II, and aldosterone during intense heat stress. Journal of Applied Physiology, 41, 323-327. doi: 10.1152/ jappl.1976.41.3.323

Kozłowski, S., \& Saltin, B. (1964). Effect of sweat loss on body fluids. Journal of Applied Physiology, 19(6), 1119-1124. doi: 10.1152/jappl.1964.19.6.1119

Kukkonen-Harjula, K., \& Kauppinen, K. (2006). Health effects and risks of sauna bathing. International Journal of Circumpolar Health, 65(3), 195-205. doi: 10.3402/ijch.v65i3.18102

Kunutsor, S.K., Powles, J.W. (2010). The effect of ambient temperature on blood pressure in a rural West African adult population: a cross-sectional study. Cardiovascular Journal of Africa, 21(1), 17-20.

Laukkanen, T., Kunutsor, S., Kauhanen, J., \& Laukkanen, J.A. (2016). Sauna bathing is inversely associated with dementia and Alzheimer's disease in middle-aged Finnish men. Age \& Ageing, 46(2), 245-249. doi: 10.1093/ageing/afw212.

Laukkanen, T., Kunutsor, S.K., Zaccardi, F., Lee, E., Willeit, P., Khan, H., \& Laukkanen, J.A. (2018). Acute effects of sauna bathing on cardiovascular function. Journal of Human Hyprtension, 32, 129-138. doi: 10.1038/s41371-017-0008-z

Lee, P.H., Macfarlane, D.J., Lam, T.H., \& Stewart, S.M. (2011). Validity of the international physical activity questionnaire short form (IPAQ-SF): A systematic review. International Journal of Behavioral. Nutrition and Physical Activity, 8, 115. doi: 10.1186/1479-5868-8-115

Leppäluoto, J., Tuominen, M., Väänänen, A., Karpakka, J., \& Vouri, J. (1986). Some cardiovascular and metabolic effects of repeated sauna bathing. Acta Physiologica Scandinavica, 128(1), 77-81. doi: 10.1111/ j.1748-1716.1986.tb07952.x

Luuira, O.J. (1980). Arrhythmias and other cardiovascular responses during Finnish sauna and exercise testing in healthy men and post-myocardial infarction patients. Acta Medica Scandinavica. Suplementum, 64, 1-60.

Miyamoto, H., Kai, H., Nakamura, H., Osada, K., Mizuta, Y., Matsumoto, A., \& Imazumi, T. (2005). Safety and efficacy of repeated sauna bathing in patients with chronic systolic heart failure: a preliminary report. Journal of Cardiac Failure, 11(6), 432-436. doi: 10.1016/j.cardfail.2005.03.004

Montain, S.J., \& Coyle, E.F. (1992). Influence of graded dehydration on hyperthermia and cardiovascular drift during exercise. Journal of Applied Physiology, 73, 1340-1350. doi: 10.1152/jappl.1992.73.4.1340

Ohori, T., Nozawa, T., Ihori, H., Shida, T., Sobajima, M., Matsuki, A., Yasumura, S., \& Inoue, H. (2012). Effect of repeated sauna treatment on exercise tolerance and endothelial function in patients with chronic heart failure. American Journal of Cardiology, 109, 100-104. doi: 10.1016/j.amjcard.2011.08.014

Peiffer, J.J., Abbiss, C.R., Watson, G., Nosaka, K., \& Laursen P.B. (2008). Effect of a 5-min cold-water immersion 
recovery on exercise performance in the heat. British Journal of Sports Medicine, 44(6), 461-465. doi: 10.1136/bjsm.2008.048173

Pilch, W., Szyguła, Z., Klimek, A., Pałka, T., Cisoń, T., Pilch, P., \& Masafumi, T. (2010). Changes in the lipid profile of blood serum in women taking sauna baths of various duration. International Journal of Occupational Medicine and Environmental Health, 23(2), 167-174. doi: 10.2478/v10001-010-0020-9

Pilch, W., Szyguła, Z., Tori, M., \& Hackney, A. (2008). The influence of hyperthermia exposure in sauna on thermal adaptation and select endocrine responses in women. Medicina Sportiva, 12(3), 103-108. doi: 10.2478/v10036-008-0020-z

Podstawski, R., Boraczyński, T., Boraczyński, M., Choszcz, D., Mańkowski, S., \& Markowski, P. (2014). Sauna-induced body mass loss in young sedentary women and men. Scientific World Journal, 307421, doi: $10.1155 / 2014 / 307421$

Podstawski, R., Boraczyński, T., Boraczyński, M., Choszcz, D., Mańkowski, S., \& Markowski, P. (2016). Saunainduced body mass loss in physically inactive young women and men. Biomededica Human Kinetics, 8, 1-9. doi: 10.1515/bhk-2016-0001

Podstawski, R., Borysławski, K., Clark, C.C.T., Choszcz, D., Finn, K.J., \& Gronek, P. (2019). Correlations between repeated use of dry sauna for 4x10 minutes, physiological parameters, anthropometric features, and body composition in young sedentary and overweight men: health implications. BioMed Research International, 2019, 7535140, doi: 10.1155/2019/7535140

Podstawski, R., Choszcz, D., Honkanen, A., Tuohino, A., \& Kolankowska, E. (2016). Socio-Economic Factors And Psycho-physical well-being as predictors of sauna use among male university students. South African Journal on Research in Sport, Physical Education and Recreation, 38(3), 153-166. doi: 10520/EJC199885

Rismann, A., al.-Karawi, J., \& Jorch, G. (2002). Infants physiological response to short heat stress during sauna bath. Clinical Pediatrics, 214, 132-135. doi: 10.1055/s-2002-30149

Sawicka, A., Brzostek, T., \& Kowalski, R. (2007). Effects of sauna on the cardiovascular system. Medical Rehabilitation, 11(1), 15-22.

Sawka, M.N., Young, A.J., Francesconi, R.P., Muza, S.R., \& Pandolf, K.B. (1985). Thermoregulatory and blood responses during exercise at graded hypohydration levels. Journal of Applied Physiology, 59, $1394-1401$. doi: 10.1152/jappl.1985.59.5.1394

Scoon, G.S.M., Hopkins, W.G., Mayhew, S., Cotter, J.D. (2007). Effect of post-exercise sauna bathing on the endurance performance of competitive male runners. Journal of Science and Medicine in Sport, 10(4), 259262. doi: 10.1016/j.jsams.2006.06.009

Šrámek, P., Šimečková, M., Janskȳ, L., Savliková, J., \& Vybiral, S. (2000). Human physiological responses to immersion into water of different temperatures. European Journal of Applied Physiology, 81, 436-442.

Tei, C, Tanaka, N. (1996). Thermal vasodilatation as a treatment of cognitive heart failure: A novel approach. Journal of Cardiology, 27(1), 29-30.

Tei, C., Horikiri, Y., Park, J.C., Jeong, J.W., Chang, K.S., Toyama, Y., Tanaka, N. (1995). Acute hemodynamic improvement by thermal vasodilation in cognitive heart failure. Circulation, 91(10), 2582-2590. doi: 10.1161/01.cir.91.10.2582

Vaile, J., O’Hagan, C., Stefanovic, B., Walker, M., Gill, N., \& Askew, C.D. (2009). Effect of cold water immersion on repeated cycling performance and limb blood flow. British Journal of Sports Medicine, 45(10), 825-829. doi: 10.1136/bjsm.2009.067272

Vuori, I. (1987). The hart and the cold. Annals of Clinical Research, 19, 156-162.

Zaccardi, F., Laukkanen, T., Willeit, P., Kunutsor, S.K., Kauhanen, J., Laukkanen, J.A. (2017). Sauna Bathing and Incident Hypertension: A Prospective Cohort Study. American Journal of Hypertension, 30, 11201125. doi: 10.1093/ajh/hpx102 